\title{
Recovery effects after extinction in the Morris swimming pool navigation task
}

\author{
JOSÉ PRADOS, RAÚL D. MANTEIGA, and JOAN SANSA \\ Universitat de Barcelona, Barcelona, Spain
}

\begin{abstract}
In three experiments in which rats were used as subjects, we developed an extinction procedure using a Morris pool. The animals were trained to find a hidden platform located at a fixed position and were then given extinction trials in which the platform was removed from the pool. When training and extinction were carried out in the same context and time was allowed to elapse between extinction and test, spontaneous recovery of learning was observed. On the other hand, those rats that received extinction in a context different from the one used for training failed to show spontaneous recovery of learning when tested in the extinction context after an interval of $96 \mathrm{~h}$. However, they did show renewal of spatial learning when tested in the training context. These results show that extinction in the spatial domain behaves like extinction in standard conditioning preparations.
\end{abstract}

Rats placed in a circular pool learn to swim toward a small platform submerged just below the surface of the water by using a cognitive map that encodes information about the relationship between the goal and several landmarks surrounding the pool (see, e.g., Morris, 1981). Spatial learning had been thought to depend on nonassociative processes (see, e.g., O' Keefe \& Nadel, 1978). However, conditions for that type of learning have been widely studied during recent years, and there is growing evidence pointing to the possible involvement of associative processes in cognitive map acquisition. Phenomena such as blocking, overshadowing, and latent inhibition have been repeatedly observed in experiments on the Morris task, thus suggesting that, at least to a certain extent, learning this navigation task could be ruled by principles similar to those involved in standard Pavlovian and instrumental conditioning tasks (see, e.g., Chamizo, 2002; Mackintosh, 2002; Prados \& Redhead, 2002).

However, as far as we know, extinction or deacquisition of spatial learning has been the subject of few studies. In standard Pavlovian preparations, presentations of the conditioned stimulus (CS) alone after conditioning result in extinction of the conditioned response. Extinction had been assumed to weaken or destroy the associations between the CS and the unconditioned stimulus (US) established during conditioning (see, e.g., Rescorla \& Wagner, 1972). However, as Rescorla (2001) pointed out, we have known since Pavlov (1927) about a variety of phenomena in which the extinguished behavior appears to be restored, which implies that extinction does not simply remove the

This research was supported by Grant BSO2001-3503 from the Spanish Ministerio de Ciencia y Tecnología. We are indebted to Nuria Vicente for her help in writing the present paper. Correspondence concerning this article should be addressed to J. Prados, Departament de Psicologia Bàsica, Universitat de Barcelona, Pg. de la Vall d'Hebron 171, 08035 Barcelona, Spain (e-mail: jprados@psi.ub.es). original learning. The present study focuses on three of these recovery effects.

First, it is well known that allowing some time to elapse after extinction and before new presentations of the CS restores the extinguished conditioned response-a typical instance of spontaneous recovery (Pavlov, 1927, p. 58). Second, this recovery of responding can be impaired by making training and extinction contexts differ. If a physical extinction cue is presented during nonreinforcement and test, the mere passage of time will not result in restored responding. This is the extinction cue effect (Brooks \& Bouton, 1993). Finally, if the CS is paired with the US in one context but is then presented alone and extinguished in a second context, a return to the original training context will renew extinguished responding to the CS-an instance of renewal (see, e.g., Bouton \& King, 1983).

The experiments reported in this paper were designed to test an extinction procedure in the Morris pool to determine whether extinction in this task behaves as it does in standard conditioning preparations. In Experiment 1, a procedure that seems to be suitable for the study of extinction in the spatial domain is reported. We also explore whether the mere passage of time after extinction might produce the recovery of the extinguished responses, as occurs in spontaneous recovery preparations. In Experiments 2 and 3 , the focus is on the role of context in the recovery of extinguished responses; the introduction of an extinction cue and the effects of the return to the original training context are tested.

\section{EXPERIMENT 1}

Two groups of rats were used in Experiment 1 in a test to determine whether extinction and spontaneous recovery can be observed in the swimming pool task. The animals were trained to find a hidden platform located at a fixed position, and then they were given extinction trials 
in which the platform was removed from the pool. After extinction, in a spontaneous recovery test four test trials were carried out to show whether accurate spatial performance could be observed when time was allowed to elapse. Rats in Group Delay-96 were tested $96 \mathrm{~h}$ after the last extinction trial, whereas those in the control groupGroup Delay-0 — were tested immediately after the last extinction trial.

\section{Method}

Subjects. Twelve male hooded Long-Evans rats (Rattus norvegicus) were used in the experiment. They had previously been used in an experiment that involved taste-aversion conditioning and were approximately 4 months old at the start of the experiment. The rats were housed in pairs in a room that was lit for $12 \mathrm{~h}$ each day. They were tested at the same time on successive days, during the period when their living quarters were lit. The rats were assigned in equal numbers to the two groups (Delay-96 and Delay-0).

Apparatus. The apparatus was a large circular swimming pool made of plastic and fiberglass, modeled after that used by Morris (1981). It measured $1.58 \mathrm{~m}$ in diameter and $0.65 \mathrm{~m}$ deep, and it was filled to a depth of $49 \mathrm{~cm}$ with water that was made opaque by the addition of $750 \mathrm{ml}$ of polystyrene latex, a nontoxic substance that does not spoil. A constant temperature of $21^{\circ} \mathrm{C} \pm 1^{\circ}$ was maintained. The pool was situated in the middle of a large room and was mounted on a wooden base $0.43 \mathrm{~m}$ above the floor. A circular platform, mounted on a rod and base, $0.11 \mathrm{~m}$ in diameter and made of transparent Perspex, could be placed in one quadrant of the pool, $0.38 \mathrm{~m}$ from the side, with its top $1 \mathrm{~cm}$ below the surface of the water. It was thus invisible to the animals. The pool was surrounded by a set of black curtains reaching from the ceiling to $0.50 \mathrm{~m}$ above the floor; the curtains formed a circular enclosure $2.40 \mathrm{~m}$ in diameter. A lighting system consisting of six low-consumption 70-W light bulbs was attached to a false ceiling, $1.75 \mathrm{~m}$ above the pool. A closed-circuit video camera with a wide-angle lens was mounted at the center of the false ceiling, and its picture was relayed to recording equipment in an adjacent room.

We used a set of four landmarks placed at equal distances around the circumference of the pool. The landmarks were A, a 40-W light placed inside a white plastic inverted cone $11 \mathrm{~cm}$ in height and $13 \mathrm{~cm}$ in diameter at the base; $\mathrm{B}$, a plastic beach ball $30 \mathrm{~cm}$ in diameter with alternate blue-white, yellow-white, and orange-white vertical segments; $\mathrm{C}$, an intermittent $1-\mathrm{W}$ light flashing on and off at a frequency of 60-80 times per minute; and D, a green plastic plant approximately $35 \mathrm{~cm}$ in diameter and $30 \mathrm{~cm}$ in height. The landmarks were suspended from the ceiling, $35 \mathrm{~cm}$ above the surface of the water and with their midlines directly above the wall of the pool. The location of the platform was always between Landmarks $C$ and D.

Procedure. There were three phases in Experiment 1: escape training, extinction, and test. Escape training consisted of five daily sessions of four escape trials with an average intertrial interval of 10-15 min. The procedure for escape training trials consisted of placing the rat into the pool surrounded by the black curtains. Each rat was given $60 \mathrm{sec}$ to find the platform, where it was allowed to stay for $30 \mathrm{sec}$. If it had not found the platform within $60 \mathrm{sec}$, it was picked up, placed on the platform, and left there for $30 \mathrm{sec}$. During each session, the rat was placed in the pool once at each of the four possible start points, each below one of Landmarks A, B, C, and D that defined the platform location. The time the rats spent in finding the platform (escape latency) was recorded.

Twenty-four hours after the final training session, the rats in Group Delay-96 were given eight consecutive extinction trials, in which the platform was removed from the pool. During the extinction trials, the rats were allowed to swim $60 \mathrm{sec}$ all around the pool while we recorded the time spent in each of four previously defined quadrants: the platform (PT) quadrant delimited by Landmarks C and $\mathrm{D}$, and the other three. Since all the rats performed at random level in the last nonreinforced trials, we considered extinction to be successfully completed. An interval of $96 \mathrm{~h}$ was then allowed to elapse and, finally, the animals were given four test trials. The procedure for test trials was exactly the same as that for extinction. The rats in Group Delay-0 were given the four test trials immediately after extinction. The eight extinction trials had been postponed $120 \mathrm{~h}$ from training, so that the time elapsed between training and test was equated for both groups.

A Type I error of $p<.05$ was used for all the statistical analyses reported in this article.

\section{Results and Discussion}

During each of the five sessions of the training phase, the two groups showed a similar pattern of results: Escape latencies were $46.38( \pm S E=2.73), 28.08$ (6.48), 30.71 (2.34), 27.71 (4.81), and 22.33 (2.95) sec for Group Delay-96 and 44.96 (6.06), 32.25 (8.06), 27.21 (6.33), 24.12 (5.78), and 28.96 (4.56) sec for Group Delay-0. An analysis of variance (ANOVA) conducted on the data with group and session as factors showed a significant effect of session $[F(4,40)=5.56]$, whereas there were no differences between groups and no significant group $\times$ session interaction.

The extinction and test results are shown in Figure 1. All the rats showed a marked preference for the PT quadrant during the first block of two extinction trials. Later on, the rats' performance decreased to chance. An ANOVA conducted on the data with group and block as factors showed a significant effect of block $[F(3,30)=5.41]$, whereas there were no differences between groups and no significant group $\times$ block interaction.

During the test phase, the animals in Group Delay-0 performed at chance, whereas those in Group Delay-96 showed a marked preference for the PT quadrant. An ANOVA conducted on the test data with group and block as factors showed a significant effect of group $[F(1,10)=$

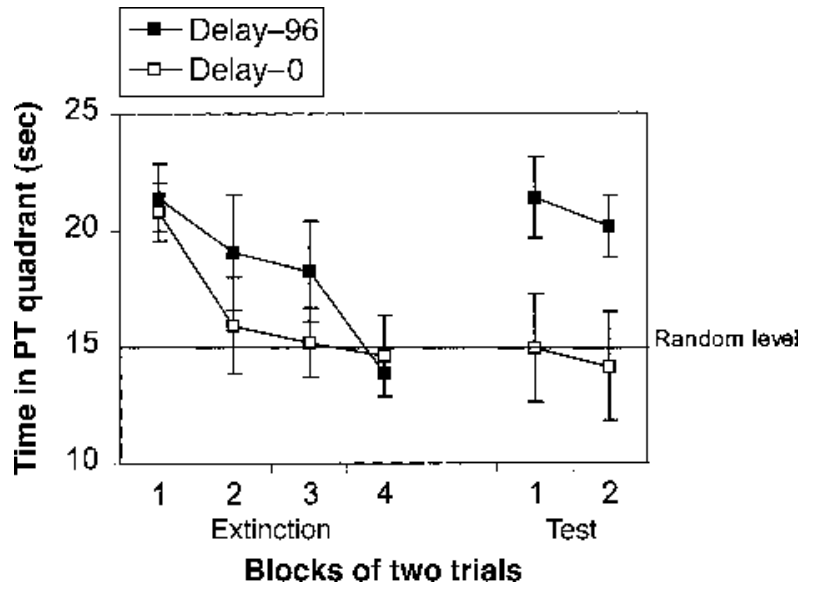

Figure 1. Mean time $( \pm S E)$ spent by Groups Delay-96 and Delay-0 in the platform (PT) quadrant over blocks of two trials during the extinction and test phases of Experiment 1. Testing took place $96 \mathrm{~h}$ after the last extinction trial for Group Delay-96, whereas there was no retention interval for Group Delay-0. 
6.24], whereas there were no differences between blocks and no significant group $\times$ block interaction.

During the first extinction trials, all the animals showed a marked preference for the PT quadrant, and this preference gradually decreased until the rats swam at random around the pool during the last extinction trials. Therefore, this procedure seems to be suitable for use in the study of extinction phenomena in the spatial domain. The preference of the animals in Group Delay-96 for the PT quadrant during the test trials can be taken as an example of spontaneous recovery of a previously extinguished spatial response. As far as we know, this is a novel finding. Spontaneous recovery of the extinguished spatial response observed in Group Delay-96 strongly suggests that the original spatial learning has not been removed during the nonreinforced trials. Thus, the well-established principles developed for standard conditioning seem to apply to navigation tasks.

\section{EXPERIMENT 2}

Experiment 2 was designed to determine whether the presence of novel physical features in the extinction phase would impair the spontaneous recovery effect observed in Experiment 1. Following the extinction cue test, we designed a further test in the original training context to obtain a renewal effect. A control group was added to the design so as to replicate the spontaneous recovery effect observed in Experiment 1.

\begin{abstract}
Method
Subjects and Apparatus. Sixteen hooded Long-Evans rats (12 males and 4 females) were used and maintained as in the previous experiment. They were divided into two groups of 8 (6 males and 2 females): Group Same and Group Different. The apparatus was the same as that used in Experiment 1. The pool was surrounded either by a set of black curtains (black context) or by a set of striped white and blue curtains (striped context) reaching from ceiling to $0.50 \mathrm{~m}$ above the floor.

Procedure. After their training in the swimming task, all the rats were given 10 extinction trials during a single session. Group Same was given extinction in the training context- that is, the black context-whereas Group Different received these extinction trials in a new, striped context. Once extinction had been completed, we allowed an interval of $96 \mathrm{~h}$. Finally, all the animals were tested twice in the extinction context, and then they received two more test trials in the original training context. Procedural details that have been omitted here were the same as those for Experiment 1.
\end{abstract}

\section{Results and Discussion}

During each of the five sessions of the training phase, the two groups showed a similar pattern of results: Escape latencies were $40.81( \pm S E=6.00), 23.34$ (3.60), 18.62 (1.62), 16.16 (1.98), and 11.5 (1.47) sec for Group Same and $47.09(3.30), 23.88(3.35), 15.50(2.18), 17.56(2.26)$, and 13.03 (3.15) sec for Group Different. An ANOVA conducted on the data with group and session as factors showed a significant effect of session $[F(4,56)=33.55]$, whereas there were no differences between groups and no significant group $\times$ session interaction.

The extinction and test results are shown in Figure 2. All the rats showed a marked preference for the PT quad- rant during the first blocks of two extinction trials. Later on, the rats' performance fell to random level. An ANOVA conducted on the data with group and block as factors showed a significanteffect of block $[F(4,56)=28.21]$ and a significant group $\times$ block interaction $[F(4,56)=6.91]$. A further simple-main-effects analysis of the group $\times$ block interaction showed that there were between-groups differences in Blocks 1 and $2\left[F_{\mathrm{s}}(1,14)>10.68\right]$, but the two groups did not differ in Blocks 3-5. Also, there were differences between blocks in both Group Same $[F(4,56)=$ $28.31]$ and Group Different $[F(4,56)=6.79]$.

During Test 1, which took place in the extinction context after $96 \mathrm{~h}$, the animals in Group Same showed a preference for the PT quadrant, whereas those in Group Different performed at random level. On Test 2, which took place immediately after Test 1 in the original training context, the performance of Group Same decreased to random level, whereas Group Different showed a marked preference for the PT quadrant. An ANOVA conducted on the test data with group and test as factors showed a significant group $\times$ test interaction $[F(1,14)=10.18]$. A further simple-main-effects analysis of the group $\times$ test interaction showed that there were differences between groups in Test $1[F(1,14)=5.36]$, and the difference between groups was nearly significant in Test $2[F(1,14)=3.68, p=.07]$. Also, there were differences between tests in both Group Same $[F(1,14)=4.74]$ and Group Different $[F(1,14)=$ 5.45].

During the first extinction trials of the present experiment, both Group Same and Group Different showed a marked preference for the PT quadrant, although later on, during the last extinction trials, both groups performed at random level. As far as Group Different is concerned, this preference for the PT quadrant at the start of the extinction phase indicates that spatial learning was transferred across

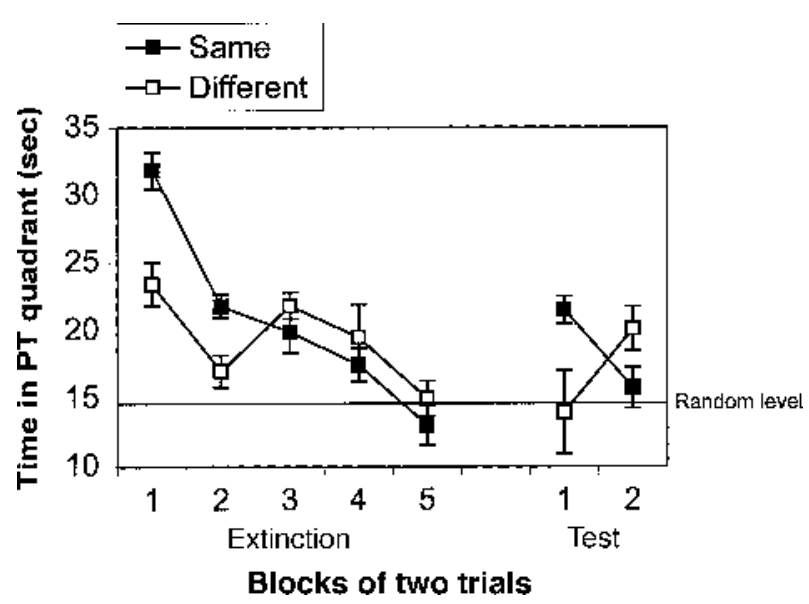

Figure 2. Mean time $( \pm S E)$ spent by Groups Same and Different in the platform (PT) quadrant over blocks of two trials during the extinction and test phases of Experiment 2. Test 1 took place $96 \mathrm{~h}$ after the last extinction trial in the extinction context; Test $\mathbf{2}$ immediately followed Test 1 and was carried out in the training context. 
contexts. However, the rats in Group Same spent more time in the PT quadrant than did the rats in Group Different, so an effect of context was observed. This result is what could be expected on the basis of the principle of generalization decrement following a context switch, and replicates the context effect that can be observed in standard appetitive conditioning tasks (e.g., Hall \& Honey, 1989; but see Bouton \& Peck, 1989).

In Test 1, which took place in the extinction context after 96 h, Group Same showed a preference for the PT quadrant, thus showing spontaneous recovery of learning. This is what we expected to happen, and it replicates the results obtained in Experiment 1. On the other hand, Group Different performed at random level during Test 1. Thus, we observed an extinction cue effect, which suggests that recovery effects are context mediated.

During Test 2, which took place immediately after Test 1 in the original training context, the performance of Group Same decreased to random level. These results contrast with those of Experiment 1, in which the rats' performance was above random level in both blocks of test trials, possibly because of the longer extinction received in Experiment 2 (five blocks of two extinction trials instead of four blocks). On the other hand, Group Different spent most of its time swimming in the PT quadrant during Test 2; that is, we observed renewal of spatial learning.

However, the renewal of learning observed in the present experiment could be criticized on the basis of the fact that the extinction context was unknown to the subjects at the beginning of the extinction phase. Processing of the novel context could have been interfering with extinction of the CS. Potentially less extinction in the Different condition would lead us to expect facilitated recovery of responding when rats are tested in the training context. Experiment 3 was designed to provide evidence of renewal by equating familiarity with the training and extinction contexts.

\section{EXPERIMENT 3}

Two groups of rats were used in Experiment 3 to determine whether renewal of learning can be observed when the extinction and training contexts are equated in both familiarity and associative strength. The rats were trained in the swimming task in two different contexts using two different arrays of cues: A, B, C, and D in the black context, and $\mathrm{L}, \mathrm{M}, \mathrm{N}$, and $\mathrm{O}$ in the striped context. The rats in Group Different were then given extinction in the alternative context (i.e., with A, B, C, and D in the striped context and $\mathrm{L}, \mathrm{M}, \mathrm{N}$, and $\mathrm{O}$ in the black context). During the final (renewal) test, which took place immediately after extinction, the landmarks were presented in their original training context. The rats in Group Same were given training, extinction, and test in the same context.

\section{Method}

Subjects and Apparatus. Sixteen male hooded Long-Evans rats were used and maintained as in the previous experiments. They were divided into two groups of 8: Group Same and Group Different. The apparatus was the same as that used in Experiments 1 and 2. A second set of landmarks was used: L, a string of colored Christmas tree lights consisting of eight $2.75-\mathrm{W}$ bulbs; $\mathrm{M}$, a white cardboard cube, $20 \mathrm{~cm}$ on edge, with a black circle $9.5 \mathrm{~cm}$ in diameter painted on each side; N, a white cardboard cone $16 \mathrm{~cm}$ in diameter and $59 \mathrm{~cm}$ in height, with 1-cm-thick black horizontal stripes spaced $3.5 \mathrm{~cm}$ apart; and $\mathrm{O}$, a vertical white plastic structure with three truncated cones of decreasing size $(22,17$, and $12 \mathrm{~cm}$ at the base and 16,12 , and $8 \mathrm{~cm}$ at the top, respectively). The location of the platform was always between $\mathrm{N}$ and $\mathrm{O}$.

Procedure. The experiment was carried out in three phases: escape training, extinction, and test. All the rats received identical training. Half of the training trials took place in the presence of the black context with A, B, C, and D as landmarks, whereas the other half took place in the striped context with $\mathrm{L}, \mathrm{M}, \mathrm{N}$, and $\mathrm{O}$ as landmarks. The rats had 10 daily sessions of four escape trials; half of the animals were trained with A, B, C, and D in the black context during the first 5 sessions and with $\mathrm{L}, \mathrm{M}, \mathrm{N}$, and $\mathrm{O}$ in the striped context during the last 5 sessions of escape training. This order of presentation was reversed for the remaining animals.

On the day after the final training session, all the animals were given eight extinction trials immediately followed by four test trials, in which the platform was removed from the pool. Half of the rats in Group Same were given extinction with A, B, C, and D in the black context, and the other half were given extinction with $\mathrm{L}, \mathrm{M}, \mathrm{N}$, and $\mathrm{O}$ in the striped context - that is, each set of landmarks was presented in its original context. In contrast, in Group Different half of the animals were given extinction with $\mathrm{A}, \mathrm{B}, \mathrm{C}$, and D in the striped context and the other half, with $\mathrm{L}, \mathrm{M}, \mathrm{N}$, and $\mathrm{O}$ in the black context. Finally, all of the animals were tested with either A, B, C, and D or $\mathrm{L}, \mathrm{M}, \mathrm{N}$, and $\mathrm{O}$ presented in their training contexts: $\mathrm{A}, \mathrm{B}, \mathrm{C}$, and D in the black context and $\mathrm{L}, \mathrm{M}, \mathrm{N}$, and $\mathrm{O}$ in the striped context.

\section{Results and Discussion}

During each of the five sessions of the training phase with $\mathrm{A}, \mathrm{B}, \mathrm{C}$, and $\mathrm{D}$ in the black context, the escape latencies were $30.68( \pm S E=2.05), 19.59(1.74), 24.03$ (2.35), 20.59 (2.2), and $17.90(2.55)$ sec. The latencies with $\mathrm{L}, \mathrm{M}, \mathrm{N}$, and $\mathrm{O}$ in the striped context were 38.37 (3.44), 30.92 (3.04), 21.84 (1.93), 18.09 (1.74), and 19.76 (2.83) sec. An ANOVA with context and session as factors showed a significant effect of session $[F(4,60)=20.65]$ and a significant context $\times$ session interaction $[F(4,60)=$ 3.91]. A further simple-main-effects analysis of the context $\times$ session interaction showed that there were differences between contexts in Session $2[F(1,15)=8.63]$. Also, there were differences between sessions both in the black context $[F(4,60)=6.82]$ and in the striped context $[F(4,60)=14.95]$.

The extinction and test results are shown in Figure 3. The rats in Group Same showed a marked preference for the PT quadrant during the first blocks of extinction trials. Later on, their performance fell to random level. In contrast, the rats in Group Different performed at random level in the first block of extinction trials and showed a marked preference for the PT quadrant in Blocks 2 and 3. Finally, they performed at random level in the last block of extinction trials. An ANOVA conducted on the data with group and block as factors showed a significant effect of block $[F(1,14)=11.08]$ and a significant group $\times$ block interaction $[F(3,42)=6.37]$. A further simple-maineffects analysis of the group $\times$ block interaction showed that there were differences between groups in Block 1 
$[F(1,14)=12.47]$, but the two groups did not differ in Blocks 2-4. Also, there were differences between blocks in both Groups Same $[F(3,42)=12.23]$ and Different $[F(3,42)=4.35]$.

During the test, which took place in the training context, the animals in Group Same performed at random level, whereas those in Group Different showed a marked preference for the PT quadrant. An ANOVA conducted on the test data with group and block as factors showed a significant effect of group $[F(1,14)=4.89]$, whereas there were no differences between blocks and no significant group $\times$ block interaction.

During the first block of extinction trials, the animals in Group Same showed a marked preference for the PT quadrant, whereas those in Group Different performed at random level. This contrasts with the results observed in the first block of extinction trials of Experiment 2, in which both groups performed at well above random level. The present results replicate the context effect observed in Experiment 2 , and the greater generalization decrement observed in Group Different in the first block of extinction trials in Experiment 3 might have resulted from greater confusion following a more difficult training task.

The preference of Group Different for the PT quadrant during the test phase constitutes a better demonstration of renewal than that reported in Experiment 2. Taken together, the results of Experiments 2 and 3 suggest that the return to the training context aids in retrieval of the training association, thereby restoring responding to the CS.

\section{GENERAL DISCUSSION}

In three experiments, we developed an extinction procedure using a Morris pool: Rats were trained to find a hidden platform located at a fixed position and were then given extinction trials in which the platform was removed from the pool. The results of the present experiments show

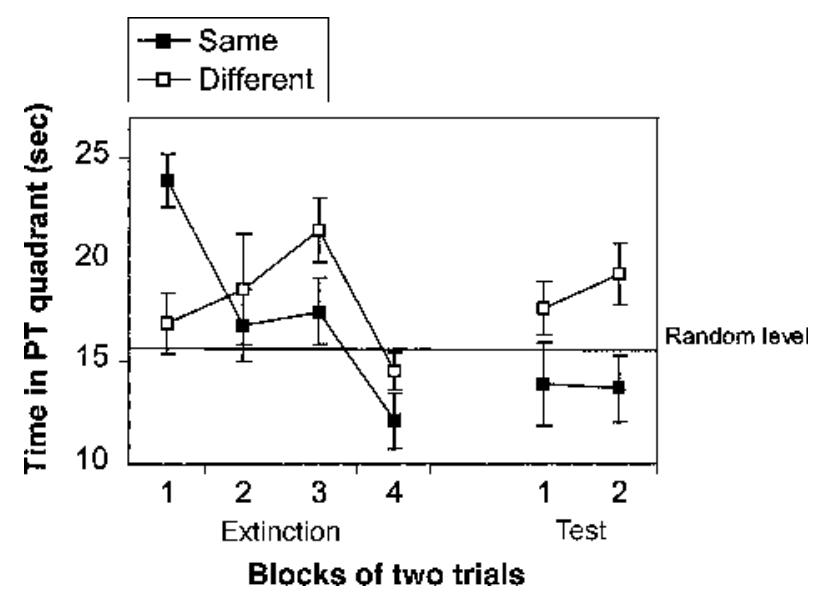

Figure 3. Mean time $( \pm S E)$ spent by Groups Same and Different in the platform (PT) quadrant over blocks of two trials during the extinction and test phases of Experiment 3. Test trials were carried out in the training context immediately after the last extinction trial. that the spatial response of approaching the platform location extinguishes during the nonreinforced swimming trials. This procedure is a suitable tool for studying the extinction phenomena dealt with in the present article.

In Experiment 1, when training and extinction were carried out in the same context and time elapsed between the last extinction trial and the test, spontaneous recovery of learning was observed. Experiment 2 showed that the presence of a physical extinction cue reduces spontaneous recovery even after a retention interval. Also, after extinction in a different novel context, a return to the training context proved to renew the extinguished spatial conditioned response. Finally, Experiment 3 provides a better demonstration of renewal than does Experiment 2, since in Experiment 3 training and extinction contexts were equated both in familiarity and in associative strength.

In Experiments 2 and 3, the rats' performance during the first extinction trials was impaired by a change of context. Instances of this context effect have been reported in the literature of both standard appetitive and aversive conditioning tasks (e.g., Archer, Sjödén, \& Nilsson, 1985; Hall \& Honey, 1989; Sjödén \& Archer, 1988, 1989), although some other studies had reported no such effect (e.g., Bouton \& King, 1983; Bouton \& Peck, 1989).

Spontaneous recovery, renewal of learning, and the extinction cue effect had previously been observed in standard appetitiveconditioning(e.g., Brooks \& Bouton, 1993), conditioned emotional response (e.g., Bouton \& King, 1983), and taste-aversion conditioning (e.g., Brooks, 2000; Brooks, Palmatier, Garcia, \& Johnson, 1999; Rosas $\&$ Bouton, 1996, 1997) preparations, among others. Given the peculiarities of the navigation task employed, the present results broaden the conditions in which these extinction phenomena can be observed.

\section{REFERENCES}

Archer, T., SJöDÉn, P., \& Nilsson, L.-G. (1985). Contextual control of taste aversion conditioning and extinction. In P. D. Balsam \& A. Tomie (Eds.), Context and learning (pp. 225-271). Hillsdale, NJ: Erlbaum.

Bouton, M. E., \& KIng, D. A. (1983). Contextual control of the extinction conditioned fear: Tests for the associative value of the context. Journal of Experimental Psychology: Animal Behavior Processes, 9, 248-265.

Bouton, M. E., \& Peck, C. A. (1989). Context effects on conditioning, extinction, and reinstatement in an appetitive conditioning preparation. Animal Learning \& Behavior, 17, 188-198.

Brooks, D. C. (2000). Recent and remote extinction cues reduce spontaneous recovery. Quarterly Journal of Experimental Psychology, 53B, 25-58.

Brooks, D. C., \& Bouton, M. E. (1993). A retrieval cue for extinction attenuates spontaneous recovery. Journal of Experimental Psychology: Animal Behavior Processes, 19, 77-89.

Brooks, D. C., Palmatier, M. I., Garcia, E. O., \& Johnson, J. L. (1999). An extinction cue reduces spontaneous recovery of a conditioned taste aversion. Animal Learning \& Behavior, 27, 77-88.

Chamizo, V. D. (2002). Spatial learning: Conditions and basic effects. Psicológica, 23, 33-58.

Hall, G., \& Honey, R. C. (1989). Contextual effects in conditioning, latent inhibition, and habituation: Associative and retrieval functions of contextual cues. Journal of Experimental Psychology: Animal Behavior Processes, 15, 232-241.

Mackintosh, N. J. (2002). Do not ask whether they have a cognitive map, but how they find their way about. Psicológica, 23, 165-185. 
Morris, R. G. M. (1981). Spatial localization does not require the presence of local cues. Learning \& Motivation, 12, 239-260.

O'KeEFE, J., \& NADEL, L. (1978). The hippocampus as a cognitive map. Oxford: Oxford University Press, Clarendon Press.

Pavlov, I. P. (1927). Conditioned reflexes (G. V. Anrep, Trans.). London: Oxford University Press.

Prados, J., \& Redhead, E. S. (2002). Preexposure effects in spatial learning: From gestaltic to associative and attentional cognitive maps. Psicológica, 23, 59-78.

Rescorla, R. A. (2001). Experimental extinction. In R. R. Mowrer \& S. B. Klein (Eds.), Contemporary learning theories (pp. 119-154). Mahwah, NJ: Erlbaum.

Rescorla, R. A., \& Wagner, A. R. (1972). A theory of Pavlovian conditioning: Variations in the effectiveness of reinforcement and nonreinforcement. In A. H. Black \& W. F. Prokasy (Eds.), Classical conditioning II (pp. 64-99). New York: Appleton-Century-Crofts.
Rosas, J. M., \& Bouton, M. E. (1996). Spontaneous recovery after extinction of a conditioned taste aversion. Animal Learning \& Behavior, 24, 341-348.

Rosas, J. M., \& Bouton, M. E. (1997). Renewal of a conditioned taste aversion upon return to the conditioning context after extinction in another one. Learning \& Motivation, 28, 216-229.

SuödÉn, P., \& Archer, T. (1988). Exteroceptive cues in taste-aversion learning, no artifact: Reply to Holder. Animal Learning \& Behavior, 16, 235-239.

SıöDÉn, P., \& ARCher, T. (1989). Taste-aversion conditioning: The role of contextual stimuli. In T. Archer \& L.-G. Nilsson (Eds.), Aversion, avoidance, and anxiety perspectives on aversively motivated behavior (pp. 87-120). Hillsdale, NJ: Erlbaum.

(Manuscript received October 16, 2002; revision accepted for publication April 22, 2003.) 